\title{
Citrullinemia Type I
}

National Cancer Institute

\section{Source}

National Cancer Institute. Citrullinemia Type I. NCI Thesaurus. Code C150601.

An autosomal recessive sub-type of citrullinemia caused by mutation(s) in the ASS1 gene, encoding argininosuccinate synthetase. 